- Editorial Notes •

\title{
Preface to the Special Issue on Fengyun Meteorological Satellites: Data, Application and Assessment
}

\author{
Peng ZHANG ${ }^{1}$, Jun $\mathrm{YANG}^{1}$, Jinsong $\mathrm{WANG}^{1}$, and Xinwen $\mathrm{YU}^{2}$ \\ ${ }^{1}$ Fengyun Meteorological Satellite Innovation Center, National Satellite Meteorological Center, \\ China Meteorological Administration, Beijing 100081, China \\ ${ }^{2}$ China Meteorological Administration, Beijing 100081, China
}

Citation: Zhang, P., J. Yang, J. S. Wang, and X. W. Yu, 2021: Preface to the special issue on Fengyun meteorological satellites: Data, application and assessment. Adv. Atmos. Sci., 38(8), 1265-1266, https://doi.org/10.1007/s00376-0211002-5.

Humans have a more than sixty-year history of observing Earth from space beginning after the launch of the first meteorological satellite, Television Infrared Observation Satellite (TIROS), in 1960. Satellite observations have transformed the way scientists observe and study Earth (Ackerman et al., 2019). With the progress of satellite data assimilation in the 1990s, modern Numerical Weather Prediction (NWP) became deeply tied to global satellite observations (Eyre et al., 1993). Scientists expect that meteorological satellites will play a more important role in future Earth Science studies.

In 1969, meteorologists first proposed the Chinese meteorological satellite program. The latest "Fengyun" (FY) satellites were named for this initial program. Modern FY satellites are both polar sun-synchronous orbiting satellites (polar hereafter) and the geostationary orbiting satellites (GEO hereafter). These satellites work in tandem to acquire measurements on global and high temporal scales. Since the first satellite (FY-1A) was successfully launched in 1988, four series have been developed, and seventeen additional satellites have been launched. The FY series, together with National Oceanic and Atmospheric Administration (NOAA) series in the U.S.A. and the polar orbiting meteorological satellite (METOP) series in Europe, has become a main pillar used to construct Earth's operational observation system (Zhang et al., 2019a).

At present, seven FY satellites operate in orbit, including three FY-2 satellites, three FY-3 satellites, and one FY-4 satellite. During the past decade, the new-generation FY polar and GEO satellites, FY-3A in 2008 (Dong et al., 2009; Zhang et al., 2009), and FY-4A in 2016 (Yang et al., 2017; Zhang et al., 2019b), have been in operation. Multiple advanced instruments are mounted on the platform of the new-generation FY satellites, including multiband optical imaging, atmospheric sounding, microwave imaging, hyperspectral trace gas detection, and full-band radiation budget measuring devices (Yang et al., 2012). Meanwhile, the second-generation satellites focus on the accuracy and precision of satellite measurements. For example, the performance of the latest polar satellite FY-3D (launched in 2017) is comparable to the well-known EOS series. High quality image navigation and radiometric calibration is essential to support various quantitative data applications, such as quantitative remote sensing and satellite data assimilation. The new epoch for comprehensive Earth observations has begun.

To facilitate domestic and international use of FY satellite data and products, the China Meteorological Administration (CMA) and China National Space Administration (CNSA) initiated the FY Satellite International User Conference. The purpose of this conference was to develop a comprehensive mechanism for international FY satellite users to exchange their applications, discuss an integrated approach to promote global applications of FY satellite data, and to better serve countries and users along the "Belt and Road". More than 200 attendees from over 30 countries participated in the first conference during 15-17 November 2019 in Haikou, Hainan Province, China.

Xian et al (2021a) summarized this initial conference, which evoked the special Advances in Atmospheric Sciences issue on "Fengyun Meteorological Satellites: Data, Application and Assessment." This special issue provides a selection of research highlights that cover all the sections of the conference:

(1) Data and products. A data description article by Xian et al. (2021b) provides the comprehensive information on Fengyun meteorological satellite products for Earth system science applications.

(2) Retrieval algorithms. Chen et al. (2021) shows the rainfall algorithms using oceanic satellite observations from WMHS-2. Wang et al. (2021a) introduces the water vapor retrievals from near-infrared channels of the advanced medium resolution spectral imager instrument onboard the Fengyun-3D satellite. 
(3) Products validation. Liu et al. (2021) introduce the assessment of FY-4A and Himawari-8 cloud top height retrieval through comparison with ground-based millimeter Radar at sites in Tibet and Beijing.

(4) NWP application. Bormann et al. (2021) report the growing operational use of FY-3 data in the ECMWF system. Carminati et al. (2021) provides the data quality and assimilation insights of the microwave instruments onboard the Fengyun 3D satellite in the Met Office NWP system. Lindskog et al. (2021) introduces the use of microwave radiances from MetopC and Fengyun-3 C/D satellites for a northern European limited-area data assimilation system. Wang et al. (2021b) shows a new way to add value of GEO-Hyperspectral infrared radiances for local severe storm forecasts using a hybrid OSSE method. Li et al. (2021) discusses the all-sky assimilation of FY-3C/MWHS-2 on Mei-yu precipitation forecasts over the Yangtze-Huaihe river basin.

(5) Climate and environmental applications. Ge et al. (2021) estimates the land surface characteristic parameters and turbulent heat fluxes over the Tibetan Plateau based on FY-4A/AGRI data.

\section{REFERENCES}

Ackerman, S. A., and Coauthors, 2019: Satellites see the world's atmosphere. Meteor. Monogr., 59, 4.1-4.53, https://doi.org/10.1175/ AMSMONOGRAPHS-D-18-0009.1.

Bormann, N., D. Duncan, S. English, S. Healy, K. Lonitz, K. Y. Chen, H, Lawrence, and Q. F. Lu, 2021: Growing operational use of FY-3 data in the ECMWF system. Adv. Atmos. Sci., https://doi.org/10.1007/s00376-020-0207-3.

Carminati, F., N. Atkinson, B. Candy, and Q. F. Lu, 2021: Insights into the microwave instruments onboard the Feng-Yun 3D satellite: Data quality and assimilation in the Met Office NWP system. Adv. Atmos. Sci., https://doi.org/10.1007/s00376-020-0010-1.

Chen, R. Y., and R. Bennartz, 2021: Rainfall algorithms using oceanic satellite observations from MWHS-2. Adv. Atmos. Sci., https://doi.org/10.1007/s00376-020-0258-5.

Dong, C. H., and Coauthors, 2009: An overview of a new Chinese weather satellite FY-3A. Bull. Amer. Meteor. Soc., 90, 1531-1544, https://doi.org/10.1175/2009BAMS2798.1.

Eyre, J. R., G. A. Kelly, A. P. McNally, E. Andersson, and A. Persson, 1993: Assimilation of TOVS radiance information through onedimensional variational analysis. Quart. J. Roy. Meteor. Soc., 119, 1427-1463, https://doi.org/10.1002/qj.49711951411.

Ge, N., L. Zhong, Y. M. Ma, Y. F. Fu, M. J. Zou, M. L. Cheng, X. Wang, and Z. Y. Huang, 2021: Estimations of land surface characteristic parameters and turbulent heat fluxes over the Tibetan Plateau based on FY-4A/AGRI data. Adv. Atmos. Sci., https://doi.org/10.1007/s00376-020-0169-5.

Li, Y., K. Y. Chen, and Z. P. Xian, 2021: Evaluation of All-Sky assimilation of FY-3C/MWHS-2 on Mei-Yu precipitation forecasts over the Yangtze-Huaihe River Basin. Adv. Atmos. Sci., https://doi.org/10.1007/s00376-021-0401-y.

Lindskog, M., A. Dybbroe, and R. Randriamampianina, 2021: Use of microwave radiances from Metop-C and Fengyun-3 C/D satellites for a northern European limited-area data assimilation system. Adv. Atmos. Sci., https://doi.org/10.1007/s00376-021-0326-5.

Liu, B., J. Huo, D. R. Lyu, and X. Wang, 2021: Assessment of FY-4A and Himawari-8 cloud top height retrieval through comparison with ground-based millimeter radar at sites in Tibet and Beijing. Adv. Atmos. Sci., https://doi.org/10.1007/s00376-021-0337-2.

Wang, L., X. Q. Hu, N. Xu, and L. Chen, 2021a: Water vapor retrievals from near-infrared channels of the advanced Medium Resolution Spectral Imager instrument onboard the Fengyun-3D satellite. Adv. Atmos. Sci., https://doi.org/10.1007/s00376-020-0174-8.

Wang, P., Z. L. Li, J. Li, and T. J. Schmit, 2021b: Added-value of GEO-hyperspectral infrared radiances for local severe storm forecasts using the hybrid OSSE method. Adv. Atmos. Sci., https://doi.org/10.1007/s00376-021-0443-1.

Xian, D., P. Zhang, M. Fang, C. Liu, and X. Jia, 2021a: The first Fengyun satellite international user conference. Adv. Atmos. Sci., https://doi.org/10.1007/s00376-020-2011-5.

Xian, D., P. Zhang, L. Gao, R. J. Sun, H. Z. Zhang, and X. Jia, 2021b: Fengyun meteorological satellite products for earth system science applications. Adv. Atmos. Sci., https://doi.org/10.1007/s00376-021-0425-3.

Yang, J., P. Zhang, N. M. Lu, Z. D. Yang, J. M. Shi, and C. H. Dong, 2012: Improvements on global meteorological observations from the current Fengyun 3 satellites and beyond. International Journal of Digital Earth, 5(3), 251-265, https://doi.org/10.1080/ 17538947.2012.658666.

Yang, J., Z. Q. Zhang, C. Y. Wei, F. Lu, and Q. Guo, 2017: Introducing the new generation of Chinese geostationary weather satellites, Fengyun-4. Bull. Amer. Meteor. Soc., 98, 1637-1658, https://doi.org/10.1175/BAMS-D-16-0065.1.

Zhang, P., and Coauthors, 2019a: Latest progress of the Chinese meteorological satellite program and core data processing technologies. Adv. Atmos. Sci., 36, 1027-1045, https://doi.org/10.1007/s00376-019-8215-x.

Zhang, P., and Coauthors, 2019b: General comparison of FY-4A/AGRI with other GEO/LEO instruments and its potential and challenges in non-meteorological applications. Frontiers in Earth Science, 6, 224, https://doi.org/10.3389/feart.2018.00224.

Zhang, P., J. Yang, C. H. Dong, N. M. Lu, Z. D. Yang, and J. M. Shi, 2009: General introduction on payloads, ground segment and data application of Fengyun 3A. Frontiers of Earth Science in China, 3(3), 367-373, https://doi.org/10.1007/s11707-009-0036-2. 